\title{
Editorial: Changing for Social Change
}

\author{
Richard F. Rakos \\ Cleveland State University
}

\begin{abstract}
Most of $B A S A^{\prime} s$ readers know that this issue is our final one, sort of. After months of negotiations befitting a corporate merger, Behaviorists for Social Action, the publisher of $B A S A$, has agreed to transfer the journal to the Cambridge Center for Behavioral Studies. Under the terms of the agreement, BASA will cease to exist, and a new journal, Behavior and Social Issues, will begin publishing in 1990, with many of the BASA editors at the helm. The goals of Behavior and Social Issues will be the same as BASA's: encouraging behavior analytic contributions to the remediation of social problems.

Many long-time $B A S A$ readers were not pleased with the transfer, and probably remain disenchanted. Unfortunately, the complexities of publishing, archiving, and distributing a journal, as well as the advertising of it, have become overwhelming, straining BFSA's behavioral and financial resources. The only other option was to simply fold $B A S A$, but after all our work, that seemed unjustified. Besides, then there would be no consistent advocate for social change from within behavior analysis. We are small, but we do have our niche.

We hope, of course, that the transfer to the Cambridge Center will enable the new journal to grow into a stronger, more effective voice for change. We are off to a good start, and the early issues of $B S I$ promise to be as lively and engaging as $B A S A$. But you can help in two ways. First, submit manuscripts (to me), and second, subscribe. BFSA members, incidentally, will get a $20 \%$ discount on subscriptions to $B S I$ by enclosing a voucher attesting to membership. All current subscribers to $B A S A$ who are members of the Association for Behavior Analysis will be considered to be members of BFSA for 1990, and will be sent a voucher. In the future, though, BFSA will have to assess token dues, enough to cover minimal operating costs until we determine the direction in which we shall head.
\end{abstract}

Change, despite the exciting possibilities, is also a time for reflection. I am disappointed that $B A S A$ can no longer forge an independant path, but proud of what we accomplished against some pretty hefty odds. In particular, we never quite recovered from The Pie Throwing Incident at an ABA convention in the early eighties. Many potential allies have assumed we belong to the Far Left violent fringe of the political spectrum and avoided us like the plague. On the other hand, we survived, even grew, during the Reagan Era, one that will surely be remembered in history with a curious mixture of horror, humor, and disbelief. (The Bush Era, by all indications, won't even be remembered. But I digress.)

$B A S A$ could not have been published over the past years without significant support from numerous people and institutions. Jerry UIman has done the most to ensure the survival of the journal: endless hours of bookkeeping, many reviews of manuscripts, and numerous submissions. Janet Ellis and Tony Marcattilio took a great deal of pressure off me by developing topical sections of the journal. And of course, Joe Morrow and Bob Jensen launched the journal and saw it through its early years.

Special thanks are offered to the Psychology Department at Ball State University, for financial and secretarial help; to the Psychology Department at Cleveland State University, also for financial and secretarial support; to Dr. Georgia LeshLaurie, Dean of Arts and Sciences at CSU, who supported the journal directly out of her Reagan-strangled budget; to the College of Arts and Sciences at CSU, for thousands and thousands of dollars (thirty?); and to Printing and Composition Services at $C S U$, for having patience with me and producing a professional journal. 